\title{
Phasor Toolbox for AC Circuit Analysis Using MATLAB
}

\section{Dr. Jai P. Agrawal, Purdue University Northwest}

Jai P. Agrawal is a professor in electrical and computer engineering technology at Purdue University, Calumet. He received his Ph.D. in electrical engineering from University of Illinois, Chicago, in 1991, dissertation in power electronics. He also received M.S. and B.S. degrees in electrical engineering from Indian Institute of Technology, Kanpur, India, in 1970 and 1968, respectively. His expertise includes analog and digital electronics design, power electronics, nanophotonics, and optical/wireless networking systems. He has designed several models of high frequency oscilloscopes and other electronic test and measuring instruments as an entrepreneur. He has delivered invited short courses in Penang, Malaysia and Singapore. He is also the author of a textbook in power electronics, published by Prentice-Hall, Inc. His professional career is equally divided in academia and industry. He has authored several research papers in IEEE journals and conferences. His current research is focused on renewable energy technology, smart energy grid.

\section{Prof. Omer Farook, Purdue University Northwest}

Omer Farook is a member of the faculty of Electrical and Computer Engineering Technology at Purdue University, Nothwest. Farook received the diploma of licentiate in mechanical engineering and B.S.M.E. in 1970 and 1972, respectively. He further received B.S.E.E. and M.S.E.E. in 1978 and 1983, respectively, from Illinois Institute of Technology. Farook's current interests are in the areas of embedded system design, hardware-software interfacing, digital communication, networking, image processing, and biometrics, C++, Python, PHP and Java languages. He has a keen interest in pedagogy and instruction delivery methods related to distance learning. He has a deep commitment to social justice and in achieving economic and educational equity.

\section{Dr. Wangling Yu, Purdue University Northwest}

Dr. Wangling Yu is an assistant professor in the Electrical \& Computer Engineering Technology Department of the Purdue University Northwest. He was a test engineer over 15 years, providing technical leadership in the certification, testing and evaluation of custom integrated security systems. He received his PhD degree in Electrical Engineering from the City University of New York in 1992, specializing in control theory and electronic technology. 


\title{
PHASOR TOOLBOX FOR AC CIRCUIT ANALYSIS USING MATLAB
}

\begin{abstract}
MATLAB is a very useful tool which can be utilized in teaching DC and AC Circuits courses. Introduction of MATLAB in the Engineering Technology program empowers the students in the early stage of their learning process. This paper presents a MATLAB phasor toolbox for analyzing ac sinusoidal circuits in the Electrical and Computer Engineering Technology program. The toolbox has functions for conversion among complex, polar and phasor forms. It includes functions for adding, subtraction, multiplication and division of phasors, plotting phasors on the complex plane and in the time domain and many useful analysis.
\end{abstract}

\section{INTRODUCTION}

DC and AC circuit analysis is the beginning and the fundamental course in the Engineering/Technology programs. In this or similar courses, students learn to analyze electrical circuits and networks by using basic electrical engineering laws like the Ohm's law, Kirchoff's laws, component relations and impedance formulae for sinusoidal signals. This analysis generally uses three steps, a) gather the given data from the word statements and list the expectations, b) use basic laws to set up the equations and steps for the analysis and c) do the calculations and plots if necessary by using formulae, mathematical tools and help at the disposal of the learner. In the last step most students and instructors and textbooks prefer to use calculators, but it is usually a long drawn procedure and often fraught with errors. In long calculations, the students often loose attention while their immediate concerns become not to commit mathematical mistakes. As a consequence, they do not pay enough attention on the concepts and the underlying reasons for doing what they are doing. This paper presents a MATLAB based Toolbox to do most of these calculations and help in fortifying the conceptual learning. Students learn to use MATLAB functions just like the mathematical formulae. The graphical displays from the tool box further enhances understanding.

\section{PHASOR TOOL BOX}

The proposed tools are designed with two objectives in mind a) to understand how to write MATLAB codes to solve a problem using standard MATLAB functions and those in the proposed toolbox, and $b$ ) to visualize the results graphically.

The toolbox contains functions that will perform most of the tasks encountered in ac and dc circuit analysis:

Conversion functions: such as the complex to polar and phasor and back.

\section{Math operations on phasors/polar variables:}

add, subtract, multiply and divide.

Complex plane plots:

of polar and phasor quantities

Time domain plots of phasors

Series-Parallel network:

determining voltage and current in all components and finding input impedances.

Thevenin and Norton equivalent circuits

Power calculations: in single and three phase circuits 
Full list of functions is as the following:

\begin{tabular}{|c|c|c|}
\hline & MATLAB function & Description \\
\hline 1 & $\mathrm{x} 2 \mathrm{p}(\mathrm{x})$ & $\begin{array}{l}\text { Conversion from Complex to Polar form, } \mathrm{x} \text { is a single complex value or } \\
\text { an array of complex values }\end{array}$ \\
\hline 2 & $\mathrm{p} 2 \mathrm{x}(\mathrm{p})$ & $\begin{array}{l}\text { Conversion from Polar to Complex form, } \mathrm{P} \text { is a single polar quantity or } \\
\text { an array of polar quantities }\end{array}$ \\
\hline 3 & $\mathrm{x} 2 \mathrm{ph}(\mathrm{x})$ & $\begin{array}{l}\text { Conversion from Complex to Phasor form, } \mathrm{x} \text { is a single complex value } \\
\text { or an array of complex values }\end{array}$ \\
\hline 4 & $\operatorname{ph} 2 x(A)$ & $\begin{array}{l}\text { Conversion from Phasor to Complex form, A is a single phasor or an ar- } \\
\text { ray of phasors }\end{array}$ \\
\hline 5 & p_conj(P) & $\begin{array}{l}\text { Conjugate of a phasor in polar form }\left(\mathrm{V}^{*}\right), \mathrm{P} \text { is a single phasor/polar } \\
\text { quantity or an array of phasor/polar quantities }\end{array}$ \\
\hline 6 & p_add(A) & $\begin{array}{l}\text { Addition of polar/phasor quantities, A is an array of polar/phasor quan- } \\
\text { tities }\end{array}$ \\
\hline 7 & p_sub(A, B) & Subtract the polar/phasor B from polar/phasor A \\
\hline 8 & p_mult(V) & Multiply polar/phasor quantities, $\mathbf{V}$ is an array of polars/phasors \\
\hline 9 & p_div(A, B) & Divide the polar/phasor $\mathbf{A}$ by $\mathbf{B}$ \\
\hline 10 & $\operatorname{xplot}(\mathrm{V})$ & $\begin{array}{l}\text { Plot complex quantity on the complex plane, } \mathrm{V} \text { is an array of complex } \\
\text { quantities }\end{array}$ \\
\hline 11 & xplot_signal( $\mathrm{x}, \mathrm{f}, \mathrm{t} 1, \mathrm{t} 2)$ & $\begin{array}{l}\text { Plot of complex variable } \mathbf{x} \text { of frequency } \mathbf{f} \text { in time domain, over a range } \\
\text { of time between } \mathrm{t} 1 \text { and } \mathrm{t} 2 \mathrm{x} \text { may be a single complex variable or an ar- } \\
\text { ray of complex variables. }\end{array}$ \\
\hline 12 & $\operatorname{phplot}(\mathrm{V})$ & $\begin{array}{l}\text { Plot of phasor on the complex plane, } \mathrm{V} \text { is a single phasor or an array of } \\
\text { phasors }\end{array}$ \\
\hline 13 & phplot_signal $(\mathrm{V}, \mathrm{f}, \mathrm{t} 1, \mathrm{t} 2)$ & $\begin{array}{l}\text { Plot of phasor } \mathbf{V} \text { of frequency } \mathbf{f} \text { in time domain, over a range of time be- } \\
\text { tween } \mathrm{t} 1 \text { and } \mathrm{t} 2, \mathrm{~V} \text { may be a single phasor or an array of phasors. }\end{array}$ \\
\hline 14 & parallelZ (Z) & $\begin{array}{l}\text { Parallel combination of two or more impedances, } \mathrm{Z} \text { is an array of im- } \\
\text { pedances in complex form }\end{array}$ \\
\hline 15 & inputZ $(\mathrm{Z}, \mathrm{V})$ & $\begin{array}{l}\text { Input impedance in complex form across a-a' terminals of the voltage } \mathbf{V} \\
\text { in a network that has an impedance matrix } \mathbf{Z}\end{array}$ \\
\hline 16 & power_ph(V,I) & $\begin{array}{l}\text { Calculate the apparent power VA, VAR, Real Power and power factor, } \\
\text { V and I are voltage and current phasors into an element or a subnetwork }\end{array}$ \\
\hline 17 & $\mathrm{Pf}(\mathrm{PT}, \mathrm{QT})$ & $\begin{array}{l}\text { Calculate the power factor in a 1-phase network that consumes real } \\
\text { power PT and reactive power QT. }\end{array}$ \\
\hline 18 & power_ph3(V,I) & $\begin{array}{l}\text { Calculate apparent power S, reactive power } \mathrm{Q} \text { and the real power } \mathrm{P} \text {, the } \\
\text { power factor Fp in a 3-phase network, } \mathrm{V} \text { and I are column of phasors in } \\
\text { all } 3 \text { phases. }\end{array}$ \\
\hline 19 & $\begin{array}{l}\text { line2phase( EAB, EBC, } \\
\text { ECA) }\end{array}$ & Line voltage to phase voltage converter in 3-phase ac circuits \\
\hline 20 & phase2line(Ean, Ebn, Ecn) & Phase voltage to Line voltage converter in 3-phase ac network \\
\hline 21 & Thevenin $(\mathrm{Z}, \mathrm{V}, \mathrm{k})$ & $\begin{array}{l}\text { Find the Thevenin equivalent circuit across a-a' terminals in a network, } \\
\mathrm{Z} \text { is the impedance matrix with terminals a-a' shorted, } \mathrm{V} \text { is source vector } \\
\text { with a-a' shorted, } \mathrm{k} \text { is the array of the loop \# where terminals a-a' are lo- } \\
\text { cated, negative loop number indicates that the loop current enters the a } \\
\text { terminal positive loop number indicates that the loop current leaves the } \\
\text { a terminal. }\end{array}$ \\
\hline 22 & delta2wye(ZA, ZB, ZC) & Delta to Wye network impedance converter in complex form \\
\hline 23 & wye2delta(Z1, Z2, Z3) & Wye to Delta network impedance converter in complex form \\
\hline 24 & pwr_triangle $(\mathrm{P}, \mathrm{Q})$ & $\begin{array}{l}\text { Draw the power triangle, the real power } \mathrm{P} \text { and the reactive power } \mathrm{Q} \text { in } \\
\text { the polar form as the base and the height and the apparent power } \mathrm{S} \text { as } \\
\text { the hypotenuse of the triangle, also calculates the power factor. }\end{array}$ \\
\hline
\end{tabular}


MATLAB is basically designed for operations on matrices and complex numbers. The toolbox specifies a complex quantity $(3+\mathrm{j} 4)$ and its graphical plot as

\section{$\mathrm{C}=3+\mathrm{j} * 4 ; \quad \% \mathrm{C}$ is a complex quantity $\operatorname{xplot}(\mathrm{C}) \quad \%$ Complex quantity $\mathrm{C}$} grid

Fig. 1 Complex quantity $\mathrm{C}$ on the complex plane

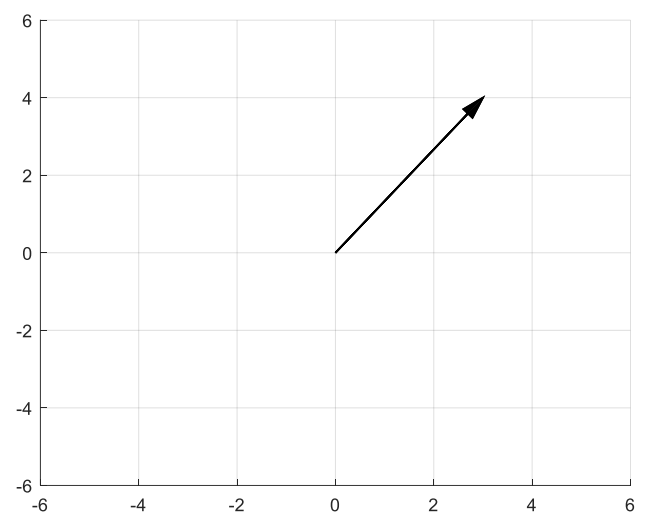

A general vector is a directed arrow from point $\mathrm{a}(\mathrm{x} 1, \mathrm{y} 1)$ to another point $\mathrm{b}(\mathrm{x} 2, \mathrm{y} 2)$ on the complex plane. Plot of a vector on the complex plane is obtained in the MATLAB from the code

$\operatorname{axis}([-6,6,-6,6])$

$\operatorname{arrow}([1,2],[4,-4])$

grid

Fig. 2 A vector on the complex plane

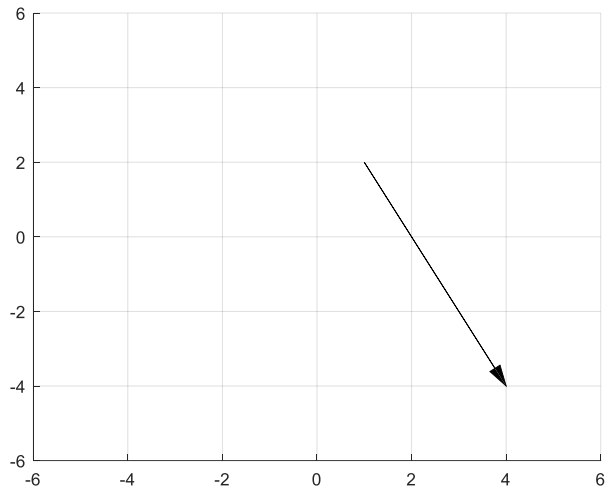

In ac circuits, an ac voltage signal is given by: $\quad v(t)=V \sin (\omega t+\theta)$

If the frequency $\omega$ is constant, the signal amplitude varies in a sinusoidal manner as time proceeds. The voltage amplitude at any time $\mathrm{t}_{1}$ can be represented by

$$
v\left(t=t_{1}\right)=V_{1}=V \cos \left(\omega t_{1}+\theta\right)+j V \sin \left(\omega t_{1}+\theta\right)
$$

Since $\omega$ is constant, we can assume it to be zero without loss of any information, then $\mathrm{V}_{1}$ can be treated as a complex quantity:

$$
V_{1}=V \cos \theta+j V \sin \theta \quad \text { in MATLAB: } V 1=\mathrm{V}^{*} \cos (\text { th })+\mathrm{j}^{*} \mathrm{~V}^{*} \sin (\text { th }) \text {; }
$$

or by a polar vector of length $\mathrm{V}$ from the origin, rotating counterclockwise on the complex plane in a circle with the center at the origin:

$$
V_{1}=V e^{j \theta} \quad \text { where } \theta \text { is denoted in radians } \quad \text { in MATLAB: } \mathrm{V} 1=\mathrm{V}^{*} \exp \left(\mathrm{j}^{*} \text { th }\right)
$$

or in ac circuit analysis by a column vector,

$$
V_{1}=V \angle \theta \quad \text { where } \theta \text { is expressed in degrees. }
$$




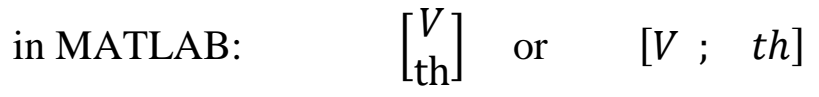

the magnitude $\mathrm{V}$ is expressed in rms, the vector $\mathrm{V}_{1}$ is called the phasor. The term phasor is reserved for expressing the sinusoidal voltage or current in polar vector format but with rms (root mean square) magnitude. Thus, a vector from origin, point ' $\mathrm{o}$ ' $(0,0)$ to a point a $(\mathrm{x}, \mathrm{y})$, is called a polar vector or a phasor.

Phasor:

Plot of a phasor on the complex plane is obtained from $\operatorname{phplot}([\mathrm{Ph}])$

The function phplot () should give the graph identical to the one obtained from cxplot().

Fig. 3 A phasor on the complex plane

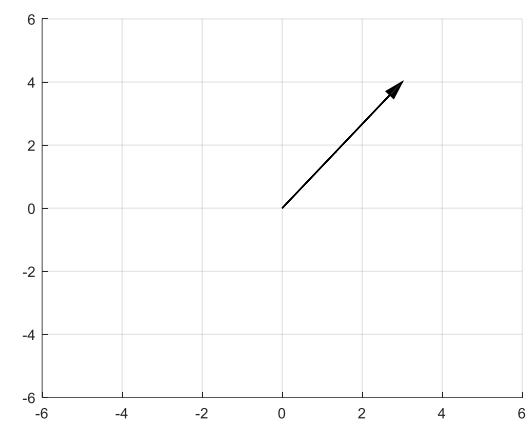

\section{Form conversions:}

Complex to polar: $\mathrm{Po}=\mathrm{x} 2 \mathrm{p}(3+\mathrm{j} * 4)$

result is

$\mathrm{Po}=[5 ; \quad 53.13]$

Complex to phasor: $\mathrm{Ph}=\mathrm{x} 2 \mathrm{ph}(3+\mathrm{j} * 4)$

result is

$\mathrm{Ph}=[3.53 ; 53.13]$

\section{ILLUSTRATIVE EXAMPLES OF AC CIRCUIT ANALYSIS}

\subsection{EXAMPLE of R-L-C Circuit}

Calculate and draw the phasor diagrams, and time domain waveforms for $I, V_{R}, V_{L}$ and $V_{C}$ in the following circuit where $\mathrm{R}=2 \mathrm{ohms}, \mathrm{L}=1 \mathrm{mH}$, and $\mathrm{C}=1000 \mu \mathrm{F}$. Assume the frequency is $60 \mathrm{~Hz}$.

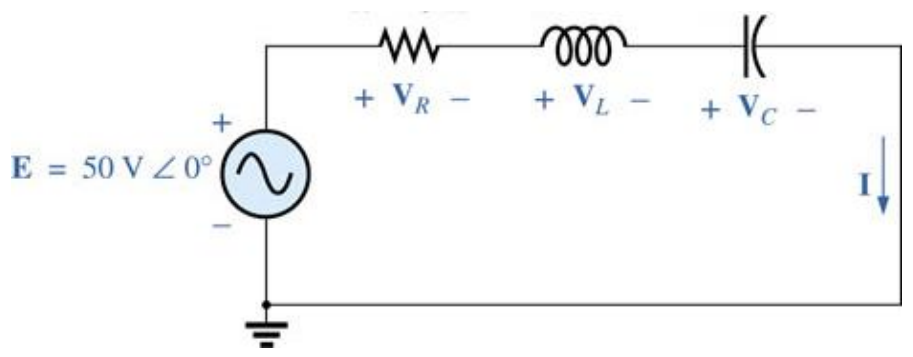

Fig. 4 A R-L-C circuit

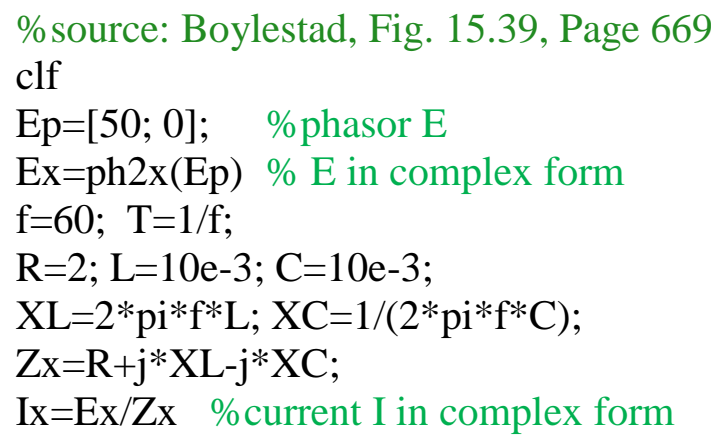


$\mathrm{Ip}=\mathrm{x} 2 \mathrm{ph}(\mathrm{Ix}) \%$ current $\mathrm{I}$ in phasor form

$\operatorname{subplot}(211)$

$\operatorname{phplot}([\mathrm{Ep}, \mathrm{Ip}])$;

grid

subplot(212)

$\%$ time domain waveforms of phasors

$\% \mathrm{E}$ and I

phplot_signal([Ep, Ip], f, 0, 2*T);

grid

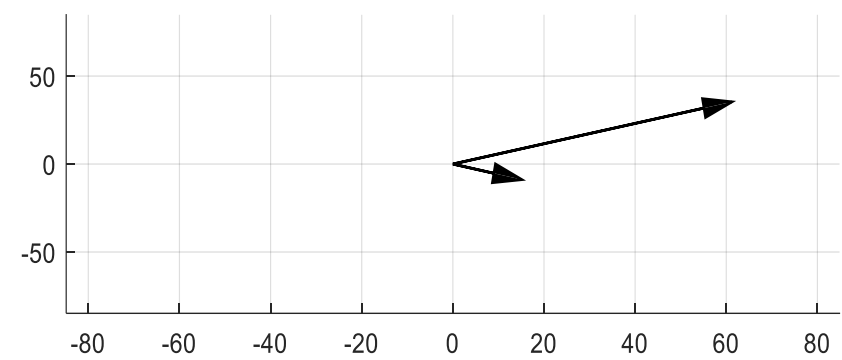

Fig. 5 Phasors and waveforms in the R-L-C circuit

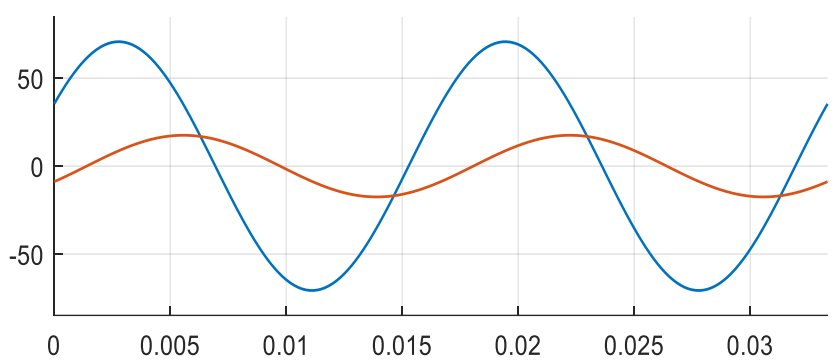

\subsection{EXAMPLE OF VOLTAGE AND CURRENT IN A NETWORK}

Find currents $I_{1}, I_{2}$, and the input impedance seen by sources $E_{1}$ and $E_{2}$.

\%source: Boylestad, Ex 18-10, Fig. 18.16, page 787

\%express all E, Z and I in the complex form

clf

$\mathrm{Z} 1=0.5+\mathrm{j} * 1 ; \mathrm{Z} 2=4-\mathrm{j} * 8 ; \mathrm{Z} 3=\mathrm{j} * 6$;

$\mathrm{f}=60 ; \mathrm{T}=1 / \mathrm{f}$;

$\mathrm{E} 1 \mathrm{p}=[8 ; 60]$;

$\mathrm{E} 2 \mathrm{p}=[10 ; 0] ;$

$\mathrm{E} 1=\mathrm{ph} 2 \mathrm{x}(\mathrm{E} 1 \mathrm{p})$

$\mathrm{E} 2=\mathrm{ph} 2 \mathrm{x}(\mathrm{E} 2 \mathrm{p})$

$\mathrm{E}=[\mathrm{E} 1+\mathrm{E} 2 ;-\mathrm{E} 2] ; \quad \% \mathrm{E}$ is a column vector

$\mathrm{Z}=[\mathrm{Z} 1+\mathrm{Z} 2, \quad-\mathrm{Z} 2$

$-\mathrm{Z} 2, \quad \mathrm{Z} 2+\mathrm{Z} 3]$

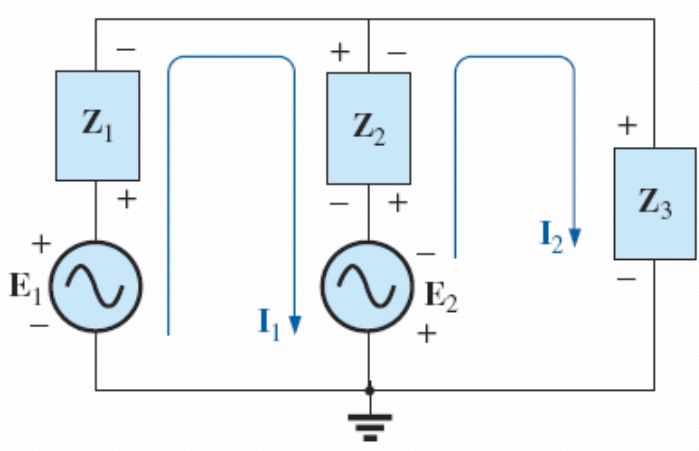

Fig. 6 A Mesh network

$\%$ solution for loop currents

$\mathrm{I}=\mathrm{Z} \mathrm{LE}$

$\mathrm{I} 1 \mathrm{p}=\mathrm{x} 2 \mathrm{ph}(\mathrm{I}(1))$

$\mathrm{I} 2 \mathrm{p}=\mathrm{x} 2 \mathrm{ph}(\mathrm{I}(2))$

subplot(411)

phplot([E1p, I1p]);

subplot(412)

phplot_t([E1p, I1p], f, 0, 2*T);

subplot(413)

phplot([E2p, I2p]);

subplot(414)

phplot_signal([E2p, I2p], f, ...

$0,2 * \mathrm{~T})$;
$\%$ Solution of $\mathrm{Z} \mathrm{I}=\mathrm{E}$ equations

\%current I1 in polar form

$\%$ current I2 in polar form 
\%input impedance as seen by source E1

$\mathrm{ET} 1=[\mathrm{E} 1 ; 0]$

\%set $\mathrm{E} 2=0$ in $\mathrm{E}$

ZT11=inputZ(Z, ET1);

$\mathrm{ZT} 1 \mathrm{p}=\mathrm{x} 2 \mathrm{p}(\mathrm{ZT} 1)$

\%input impedance as seen by source

E2

$\mathrm{ET} 2=[\mathrm{E} 2 ;-\mathrm{E} 2]$;

$\%$ set $\mathrm{E} 1=0$

ZT2=inputZ(Z, ET2);

$\mathrm{ZT} 2 \mathrm{p}=\mathrm{x} 2 \mathrm{p}(\mathrm{ZT} 2)$
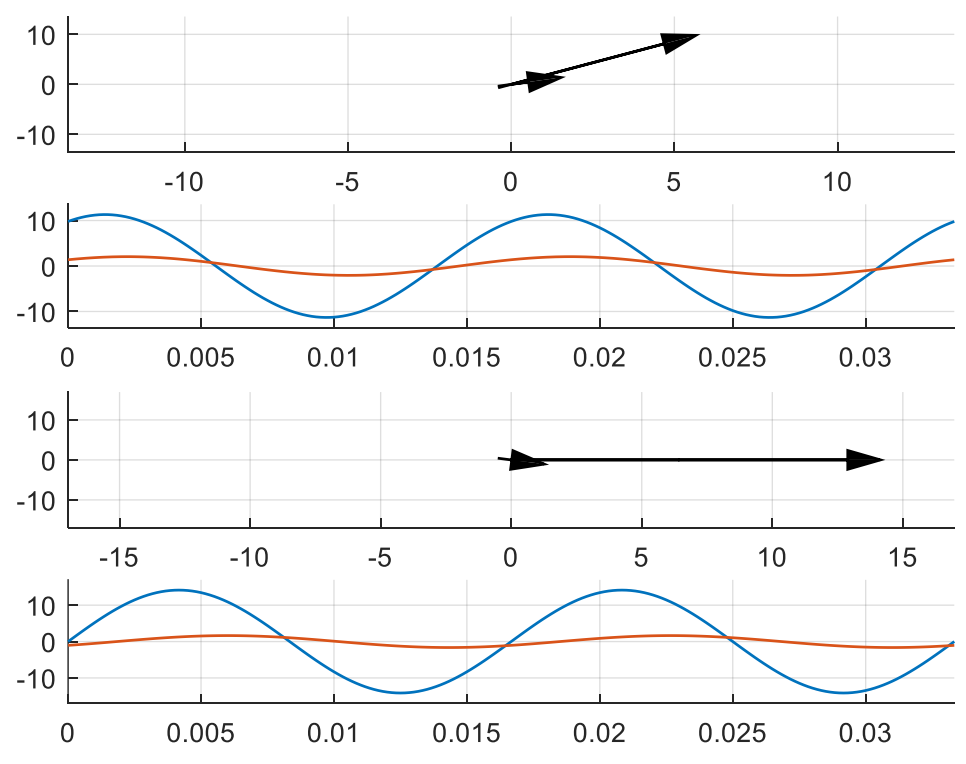

Fig. 7 Phasors and waveforms in Fig 6

\subsection{EXAMPLE OF MAXIMUM POWER TRANSFER}

Find the Thevenin equivalent circuit as seen by $\mathrm{Z}_{\mathrm{L}}$ and the maximum power delivered to it.

\%source: Boylestad, Ex 19-20, Fig.

19.85, page 849)

clf

$\mathrm{Z} 1=\mathrm{j} * 9 ; \mathrm{Z} 2=8$;

$\mathrm{Ep}=[10 ; 0] ; \% \mathrm{E}$ as phasor

$\mathrm{Ex}=\mathrm{ph} 2 \mathrm{x}(\mathrm{Ep}) ; \% \mathrm{E}$ in the complex

form

$\%$ Write $\mathrm{Z}$ matrix with the terminals

a-a' shorted

$\mathrm{V}=[\mathrm{Ex} ; 0 ; 0]$;

$\mathrm{Z}=[\mathrm{Z} 1, \quad-\mathrm{Z} 1, \quad 0$

$-\mathrm{Z} 1, \quad \mathrm{Z} 1+\mathrm{Z} 1+\mathrm{Z} 1, \quad-\mathrm{Z} 1$

$0, \quad-\mathrm{Z} 1 \quad, \quad \mathrm{Z} 1+\mathrm{Z} 2]$;

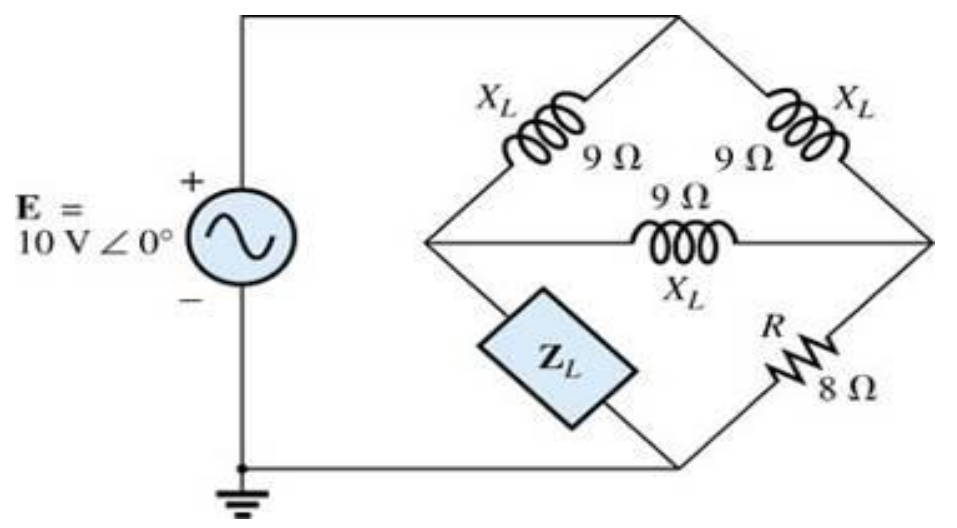

Fig. 8 Maximum Power transfer in Bridge network

$\mathrm{k}=[-1,3] ; \%$ parameter $\mathrm{k}$ in thevenin

[Eth, Zth]=Thevenin $(\mathrm{Z}, \mathrm{V}, \mathrm{k})$;

Ethp $=x 2 p h(E t h) \%$ Thevenin voltage

Zthp $=x 2 p(Z$ th $) \%$ Thevenin impedance

$\%$ ZL for for max power transfer

$\mathrm{ZL}=\operatorname{conj}(\mathrm{Zth})$

ZLp=p_conj(Zthp)

$\operatorname{Pmax}=\operatorname{Ethp}(1)^{\wedge} 2 /(4 * \operatorname{real}(Z$ th $))$

phplot([Zthp, ZLp]);

grid

Fig. 9 The Thevenin and the load impedances in the complex plane at maximum power transfer

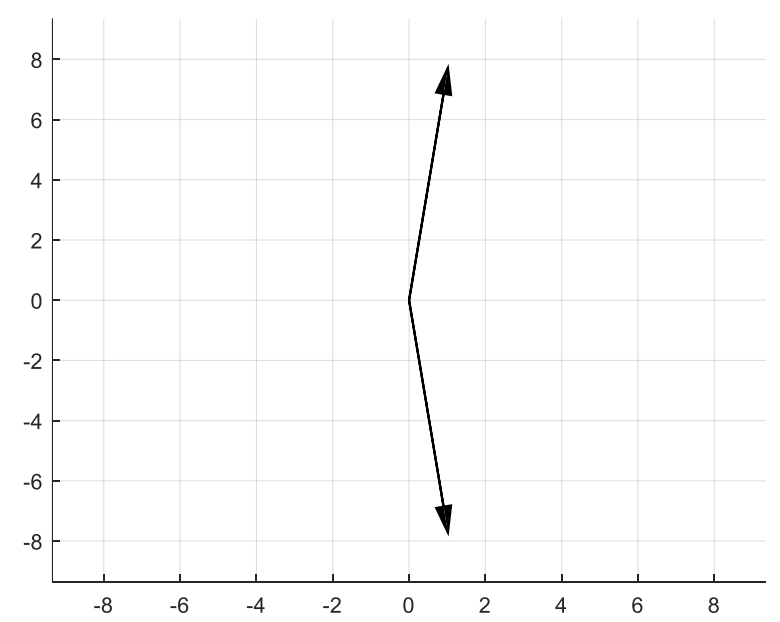




\subsection{EXAMPLE OF SUPERPOSITION OF SOURCES WITH DIFFERENT FREQUENCIES}

$E_{1}$ and $E_{2}$ are respectively the $100 \mathrm{~Hz}$ and $200 \mathrm{~Hz}$ sources. Find the current $\mathrm{I}$ in the middle branch and plot its waveform. The inductors $\mathrm{L}_{1}=6.4 \mathrm{mH}, \mathrm{L}_{2}=6.4 \mathrm{mH}$, and the capacitor $\mathrm{C}=500 \mu \mathrm{F}$.

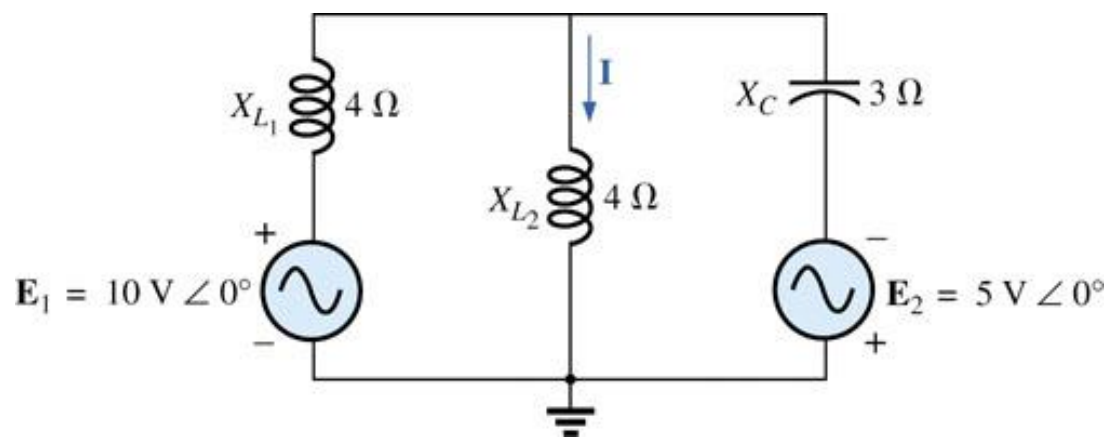

Fig. 10 A circuit with sources of different frequencies

\%source: Boylestad, Fig. 19.15, page 822

\section{\%ECET15200_ch19_1B}

clf

$\mathrm{f} 1=100 ; \mathrm{f} 2=200$;

$\mathrm{L} 1=.0064 ; \mathrm{L} 2=\mathrm{L} 1 ; \mathrm{C}=5 \mathrm{e}-4$;

$\mathrm{Z} 1=\mathrm{j} * 2 * \mathrm{pi} * \mathrm{f} 1 * \mathrm{~L} 1 ; \mathrm{Z} 2=\mathrm{Z} 1 ; \mathrm{Z} 3=-$

$\mathrm{j} /\left(2 * \mathrm{pi}^{*} \mathrm{f} 1 * \mathrm{C}\right)$;

$\mathrm{Z} 12=\mathrm{Z} 1 * \mathrm{f} 2 / \mathrm{f} 1$;

$\mathrm{Z} 22=\mathrm{Z} 2 * \mathrm{f} 2 / \mathrm{f} 1$

$\mathrm{Z} 32=\mathrm{Z} 3 * \mathrm{f} 1 / \mathrm{f} 2$;

$\mathrm{E} 1 \mathrm{p}=[10 ; 0] ; \mathrm{E} 2 \mathrm{p}=[5 ; 0]$;

$\mathrm{E} 1=\mathrm{ph} 2 \mathrm{cx}(\mathrm{E} 1 \mathrm{p}) ; \mathrm{E} 2=\mathrm{ph} 2 \mathrm{cx}(\mathrm{E} 2 \mathrm{p}] ;$

Is $1=\mathrm{E} 1 /(\mathrm{Z} 1+$ parallelZ $([\mathrm{Z} 2, \mathrm{Z} 3]))$

I1_1=Z3*Is1/(Z2+Z3)

Is2=E2/(Z32+parallelZ([Z12, Z22]))

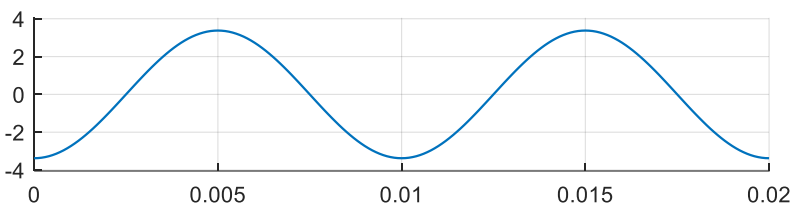

I1_2=Z12*Is $2 /(Z 12+Z 22)$

subplot(311)

[y1, t1]=xplot_signal(I1_1, f1, 0, 0.02);

subplot(312)

[y2, t2]=xplot_signal(I1_2, f2, 0, .02);

subplot(313)

plot(t1, y1+y2) \%superposed current
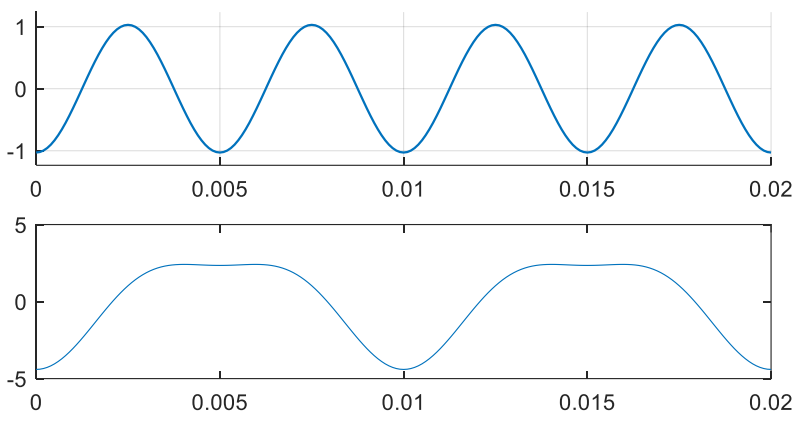

Fig. 11 Waveforms in the circuit of Fig. 10

\subsection{EXAMPLE OF 3-PHASE $\Delta$-GENERATOR, Y- $\Delta$ LOAD}

Find the total average, reactive and apparent power and the power factor. 


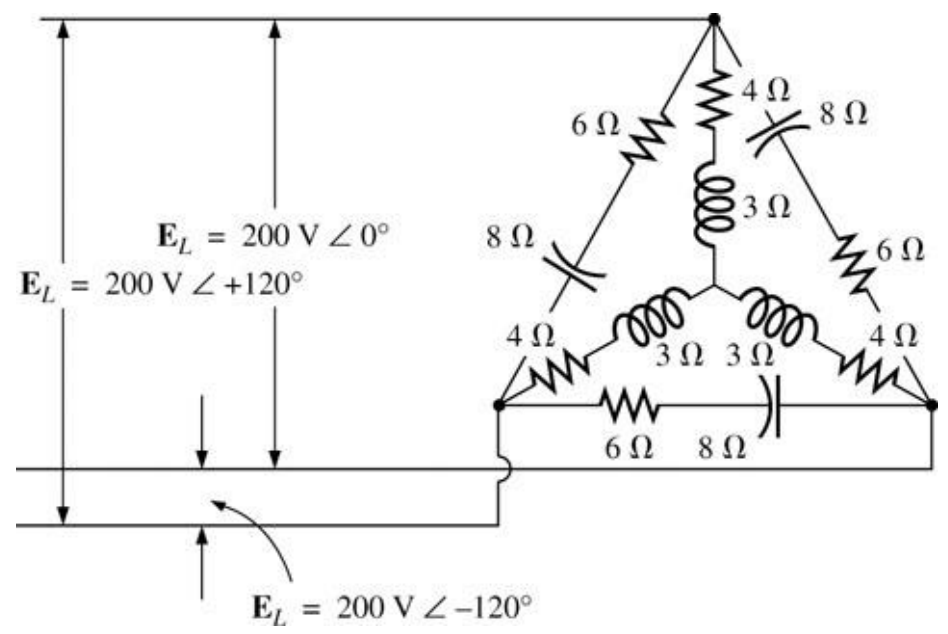

Fig. 12 3-phase $\Delta$-generator, Y- $\Delta$ load

\%source: Boylestad, Ex 24-6, Fig. 24.25, page 1094

clf

$\mathrm{f}=60 ; \mathrm{T}=1 / \mathrm{f}$;

$\%$ Delta Load

$\mathrm{EAB}=[200 ; 0] ; \mathrm{EBC}=[200 ;-120] ; \mathrm{ECA}=[200 ;-240] ; \%$ Line voltages

$\mathrm{Ed}=[\mathrm{EAB}, \mathrm{EBC}, \mathrm{ECA}]$;

$\mathrm{Zab}=\mathrm{x} 2 \mathrm{p}\left(6-\mathrm{j}^{*} 8\right) ; \mathrm{Zbc}=\mathrm{Zab} ; \mathrm{Zca}=\mathrm{Zab} ; \%$ impedances in the Delta Load, converted to the complex... form

$\%$ Calculation of Line currents in the Delta load

$\operatorname{Idab}=p \_d i v(E A B, Z a b) ; \operatorname{Idbc}=p \_d i v(E B C, Z b c) ; \operatorname{Idca}=p \_d i v(E C A, Z c a)$;

Id $=[$ Idab, Idbc, Idca];

[STd, QTd, PTd]=power_ph3d(Ed, Id) \%apparent, reactive and the average power in the Delta load

$\%$ Y-load calculations

$\mathrm{Zan}=\mathrm{x} 2 \mathrm{p}(4+\mathrm{j} * 3) ; \mathrm{Zbn}=\mathrm{Zan} ; \mathrm{Zcn}=\mathrm{Zan}$;

[Van, Vbn, Vcn]=line2phase(EAB, EBC, ECA)

$\mathrm{V}=[\mathrm{Van}, \mathrm{Vbn}, \mathrm{Vcn}]$;

Ian=p_div(Van, Zan $)$ I Ibn=p_div(Vbn, Zbn); Icn=p_div(Vcn, Zcn);

$\mathrm{I}=[\mathrm{Ian}, \mathrm{Ibn}, \mathrm{Icn}]$;

[STy, QTy, PTy]=power_ph3d(V, I) \%apparent, reactive and the average power in the Y-load

\%full load calculations

PT=p_add([PTd, PTy $])$

QT=p_add([QTd, QTy])

[ ST, Fp, phase]=pwr_triangle(PT, QT ) 


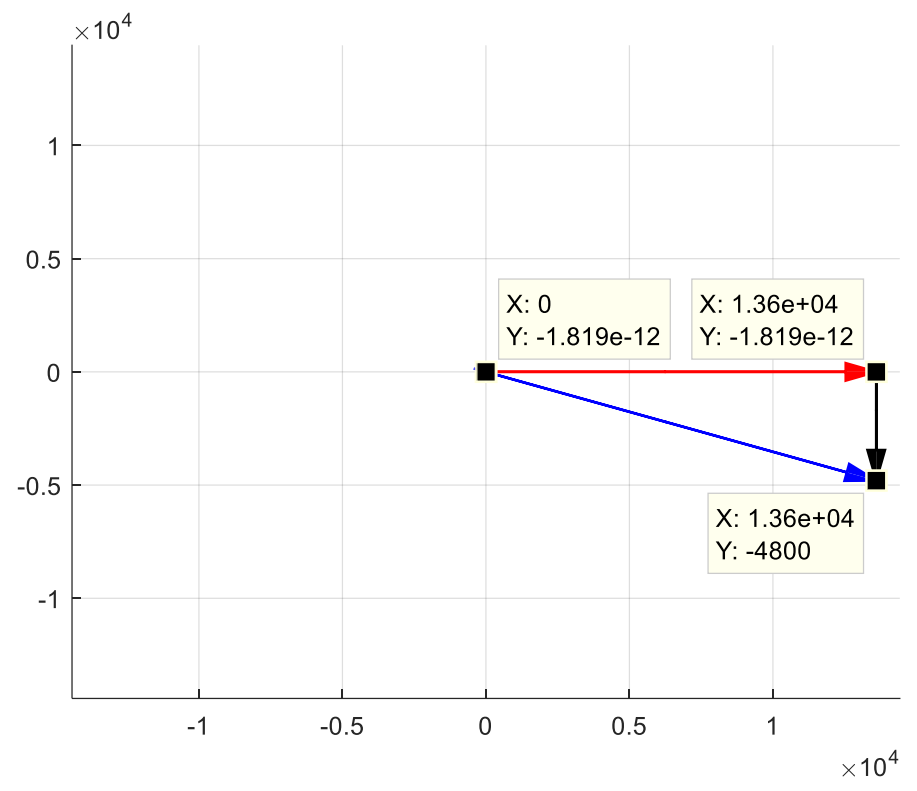

Fig. 13 The apparent, reactive and the average power in the 3-phase $\Delta$-generator, Y- $\Delta$ load

\section{PLAN OF IMPLEMENTATION}

The phasor toolbox was developed while teaching the class in the Fall semester of 2017. It is planned to use the tool in ECET 15200: AC Circuit Analysis, ECET 21200: Electrical Power and Machinery, and ECET 41200: Electric Drives in the future semesters in the Electrical Engineering Technology undergraduate program. We plan to look at the effect on the content delivery and assess the benefits of instruction by utilizing the Phasor Tool Box. All user defined functions will be made available to those who ask for them.

\section{SUMMARY}

This paper presents a MATLAB phasor toolbox for analyzing ac sinusoidal circuits in the Electrical and Computer Engineering Technology program. The toolbox has functions for conversion among complex, polar and phasor forms, for adding, subtraction, multiplication and division of phasors, plotting phasors on the complex plane and in their waveforms in the time domain. The toolbox also enables the calculation of Thevenin equivalent circuits, input impedances in networks, and calculation of apparent, reactive and real power in single and 3-phase ac circuits. The toolbox has the capability of analyzing ac circuits with sources of different frequencies. It is also capable of drawing Power Triangle diagrams and power factors in 3-phase networks.

\section{References}

[1] "Introductory Circuit Analysis" Robert Boylestad, 13"th ed., Pearson Education Inc.

[2] MATLAB v. 2017b, Mathworks Inc. 